\title{
Bovine Babesiosis and Distribution of ixodid ticks in Dasenech and Salamago District, Southern Ethiopia
}

\author{
Haben Fesseha ${ }^{1 *}$, Mesfin Mathewos ${ }^{1}$, Eyob Eshetu $^{1}$, Bereket Tefera $^{2}$ \\ ${ }^{1}$ School of Veterinary Medicine, Wolaita Sodo University, Wolaita Sodo, Ethiopia \\ 2 Jinka town Municipal Animal health team leader, South Omo Zone, Jinka, Southern Ethiopia \\ *Correspondence: Haben Fesseha, E-mail: haben.senbetu@wsu.edu.et
}

\begin{abstract}
Background: Babesiosis and its tick carriers cause serious problems for cattle and are among the common protozoan blood parasites in Ethiopia.

Methods: A cross-sectional survey was conducted from September 2019 to August 2020 to identify babesiosis in cattle and its tick vectors in extensively managed livestock in Dasenech and Salamago District South Omo Ethiopia. A total of 470 blood samples were collected for identification of hemoparasite using a thin blood smear followed by the Giemsa staining method and Packed Cell Volume (PCV) determination for detection of anemia.

Results: Accordingly, the overall prevalence of bovine babesiosis in the study districts were $21.7 \%$ and Babesia bigemina (15.53\%) and B. bovis (6.17\%) were identified during this study. Factors such as age, sex, body condition score, season, tick burden, and level of tick Infection were considered as risk factors; yet, the season and level of tick Infection were found significantly associated $(p<0.05)$ with the occurrence of babesiosis. Besides, the mean PCV value of infected cattle (21.49\%) was lower than non-infected animals $(28.29 \%)$ which shows there was a strong correlation $(p=0.0001)$ between anemia and Babesiosis. The prevalence of tick Infection was $86.17 \%(405 / 470)$ and a total of 8040 ticks adult ticks belonging to four tick genera namely Amblyomma (32.34\%), Boophilus (18.51\%), Hyalomma (18.94\%), and Rhipicephalus (16.38\%) were identified and all have a significant role ( $\mathrm{p}<$ $0.05)$ on the occurrence of babesiosis in cattle.

Conclusion: Bovine babesiosis is an important hemoparasitic protozoan disease of cattle in the study areas. To address and manage the problem, nearby veterinary service systems need to diagnose blood parasites and provide alternatives, especially for tick-borne diseases. Also, it is essential to customize appropriate and integrated tick control measures and tactical treatment of overt bovine babesiosis clinical cases.
\end{abstract}

Keywords: Babesiosis, Cattle, Host factors, Prevalence, Tick Infection, South Omo

\section{INTRODUCTION}

Ethiopia has one of the largest livestock populations in Africa, and livestock production is critical to the country's agricultural development. For instance, there are about 56.1 million heads of cattle in Ethiopia representing a huge population of animals in Africa [1]. Despite the importance of animal 
production to the economy as a whole, this sub-sector remains underutilized. In addition, the region contributes significantly to some of the country's problems. This includes illness, old age, poor husbandry practice, poor genetic makeup, and malnutrition, and is complicated by malnutrition, harsh environments, and lack of market infrastructure [2-4].

Animal diseases are a major factor affecting productivity and productivity and adversely affect livestock health. The presence of parasitic diseases in the blood is largely related to the presence and distribution of their vectors. Arthropod transmitted haemoparasitic disease of cattle that are caused by Babesia, Trypanosome, Theileria, and Anaplasma species. These infectious blood parasitic conditions of arthropods are economically necessary vector-borne pathogens in tropical and subtropical regions of the world, including Ethiopia [5, 6].

Bovine babesiosis is the most common bovine arthropod disease in the world, causing enormous morbidity and mortality. It is the second blood-borne parasite in mammals after trypanosomes and was previously classified as a List B-ailment by OIE. The most common species, B. bovis and B. bigemina, are discovered at some point in most tropical and subtropical regions, specifically vital in Asia, Africa, Central and South America, components of southern Europe and Australia [4]. Although B. bovis is commonly observed in the equal usual geographic area as B. bigemina, barely special organizations of ticks unfold these two species, and some variations in their distribution can be seen. For example, $B$. bigemina is greater widely dispensed than B. bovis in Africa. The monetary losses from these two organisms can be considerable, particularly in growing countries. Although babesiosis can be managed with vaccination and dealt with antiparasitic drugs, the vaccines are live and have security issues and many fantastic pills have been withdrawn from the market due to security or residue issues [7].

Bovine babesiosis is a tick-borne hemoparasitic disease instigated by an intraerythrocytic protozoan parasite known as babesia, resulting in substantial morbidity and mortality in cattle and buffaloes [8]. Taxonomically, Babesia belongs to the phylum Apicomplexa, orders Piroplasmida, and subclass Piroplamsia and are mostly referred to as 'piroplasmas' due to the pear-like formed merozoites. More than one hundred known Babesia species have been recognized which infect many sorts of the mammalian host, out of these, 18 of them cause disorder in-home animals incredibly in cattle, sheep, goats, horses, pigs, dogs, and cats [9]. The main Babesia species that affect cattle consist of Babesia bigemina, Babesia bovis, Babesia divergens, and Babesia major. Two species, B. bigemina, and $B$. bovis have a vast effect on cattle health and productiveness in tropical and subtropical nations [10].

Babesia bovis infections are characterized by excessive fever, ataxia, anorexia, time-honored circulatory shock, and once in a while also nervous symptoms as a result of sequestration of infected erythrocytes in cerebral capillaries. This disease causes anemia and hemoglobinuria especially in the later stage of the disease. In acute cases, the most parasitemia (percentage of infected erythrocytes) in circulating blood is much less than $1 \%$. This is in distinction to B. bigemina infections, in case the parasitemia often exceeds $10 \%$ and may be as excess as $30 \%$. In B. bigemina infections, the fundamental symptoms encompass fever, hemoglobinuria, and anemia. Infected animals enhance life- 
long immunity towards reinfection with the equal species of Babesia. There is also evidence of a degree of cross-protection in B. bigemina-immune animals against subsequent $B$. bovis infections. Calves hardly ever show clinical symptoms of the disease after infection regardless of the babesia species concerned or the immune popularity of the dams [11].

Ticks are one of the most common parasites in the world and are the major carriers of animal diseases, especially in the tropical and subtropical regions of the world. As a parasite, ticks cause tick-borne diseases, anemia, irritation, skin abrasions, tick poisoning, bites, sores, and muscle relaxants, and udder loss, and teat injury, which predisposes to secondary bacterial infections [12, 13]. Several investigations have been performed on the ticks and tick-borne disease of cattle in various parts of Ethiopia and various species of ticks belonging to the genus Amblyomma, Rhipicephalus (Boophilus), Rhipicephalus, Hyalomma, and Haemaphysalis have been identified [14-22]. Domestics and wild animals are infected by more than 60 tick species and 33 of these are considered as major parasites of livestock [23].

Earlier studies performed on the distribution, abundance, and occurrence of hemoparasite species affecting farm animals in various parts of Ethiopia have proven the considerable existence of hemoparasite like anaplasmosis, babesiosis, cowdriosis, trypanosomosis and theileriosis (T. mutans) $[3,8]$. In Ethiopia, several investigations have been carried out on distribution, abundance, and incidence of hemoparasite species on cattle in several areas of Ethiopia by a variety of investigators consisting of cattle trypanosomosis, babesiosis in donkeys, and dogs [16, 20, 24-27]. So far, no detailed research was conducted in Dasenech and Salamago District as to the assessment of the extent, magnitude, and distribution of bovine babesiosis and its tick vectors. Hence, in light of the above background information and justifications, the current study was conducted to address the status of bovine babesiosis and its tick vectors in Dasenech and Salamago District.

\section{MATERIALS AND METHODS}

\subsection{Study Sites}

The study was conducted in the Salamago and Dasenech district of South Omo Zone, the Southern Nation Nationalities and Peoples Regional State (SNNPRS) of Ethiopia, and it is located 110km from Jinka, the city of South Omo zone, and $597 \mathrm{~km}$ from Hawassa, the city of SNNPRS. The district covers about $451,120 \mathrm{~km}^{2}$. According to the Salamago wereda pastoral and rural development office (2019/2020), the climatic condition of the wereda ranges from arid to sub-humid. The average temperature and humidity of the study area are $32^{\circ} \mathrm{C}$ and $977 \mathrm{mmHG}$, respectively. The grass and bushland and some domestic trees like acacia were found in the study area [28].

Dasenech district is located 206km from zone capital Jinka, $642 \mathrm{~km}$ from the region capital Hawassa and $956 \mathrm{~km}$ from Addis Ababa and found near the Kenyan border. This area has a latitude and longitude of $4^{0} .45^{\prime}-4^{0} .99^{\prime} \mathrm{N}$ and $35^{0}$ ' $81^{\prime}-36^{\circ} .41^{\prime} \mathrm{E}$, respectively. The Dasenech is found in Omo Delta 
and this is an incredibly dry region with a temperature ranging up to $35^{\circ} \mathrm{C}$ and cattle are central to the lives of the community. The areas have a livestock population of 640,500 cattle, 224,537 sheep, 282,427 goats, 22,400 donkeys, 350 camels, and 23,412 poultry. The woreda practice predominantly pastoralism with a little rainfed and irrigation agriculture [1].

\subsection{Study Animals and Design}

In this study, the study animals were indigenous cattle of both sexes, various age groups, body conditions, and various hair coat colors that were managed under an extensive management scheme with communal herding. Cattle were categorized as young, adult, or old based on dentition. Those animals without erupted permanent incisor teeth have been categorized as young, whilst those with one or extra pairs of erupted permanent incisor tooth had been labeled as adult and old [29, 30].

The body condition score was determined to be good, medium, and poor on the basis of the presence of the ribs and dorsal spines [31]. The studied animals were split into five classes of white, red, black, and mixed coat colors, to determine whether the coat color of the animal had any effect on the occurrence of the disease [32]. The cross-sectional research was undertaken from September 2019 to August 2020 to assess the prevalence of babesiosis in cattle and estimate possible epidemiological risk factors.

\subsection{Sample Size Determination and Sampling Technique}

The sites were selected on the basis of available cattle population and ease of transportation and environmental condition, selected sites (Peasant Association) were identified and selected based on convenience. The study cattle were selected randomly from each locality. The sample size of this parasitological survey was measured with a $95 \%$ confidence interval and 5 percent precision and an estimated or expected prevalence and calculated using Thrusfield, [33].

$\mathrm{n}=\frac{1.96^{2} \operatorname{Pexp}(1-\mathrm{Pexp})}{\mathrm{d}^{2}}$

Where; $\mathrm{n}=$ required sample size, Pexp =expected prevalence $(50 \%), \mathrm{d}=$ desired absolute precision.

Accordingly, as per the predetermined parameters, the sample size computed was 384 cattle. To increase the precision of the study, a total of 470 cattle were sampled during the study. Moreover, the prevalence for each tick species was calculated as $\mathrm{P}=\mathrm{d} / \mathrm{n} \times 100$, where $\mathrm{p}=$ the prevalence, $\mathrm{d}=$ Number of animals that tested positive for particular tick genera, and $\mathrm{n}$ - the total number of animals collected from animal species [34].

\subsection{Study Methodology}

\subsubsection{Tick collection and identification}

Ticks were collected by forceps and gloved handpicking by a simple random sampling method from different body parts of the cattle without damaging their mouthparts. The collected ticks were 
preserved in 70\% ethyl alcohol in clean, well-stopped glass vials and labeled properly. Morphological characterization of ticks was carried out using a stereoscopic microscope [35].

\subsubsection{Collection and Examination of blood sample}

The blood samples of 470 cattle were collected with heparinized capillary tubes from the external jugular vein and marginal ear vein after disinfecting with $70 \%$ alcohol and had been sealed with wax at one end for hematological analysis. All parasitological diagnostic tests and procedures were conducted as described by Paris et al., [36] and Bock et al. [11]. After being labeled, they were transported with an icebox to the Jinka Veterinary regional Laboratory, where the samples were collected from the field.

\subsubsection{Determination of Parasitemia and Packed cell volume (PCV)}

Packed cell volume, which is a measure of the percentage of whole blood volume occupied by red blood cells, was determined by microhematocrit centrifugation. [37]. The micro-hematocrit capillary tubes (up to $34^{\text {th }}$ ) were filled with blood with a sealed end outermost. The blood specimens were centrifuged at 12,000 rpm for 5 minutes using a hematocrit centrifuge [38]. To assess the degree of anemia, the packed cell volume was measured using a hematocrit reader. The capillary tubes were then removed using a diamond tip pen $1 \mathrm{~mm}$ below the buffy coat covering the top layer of red blood cells and containing plasma $3 \mathrm{~mm}$ above. The contents were displayed on a clean, well-mixed microscope slide and covered with a $22 \times 22 \mathrm{~mm}$ coverslip [39]. After centrifugation, the capillaries were put into the hematocrit reader for hematocrit (PCV) measurements, expressed as a percentage of the total blood volume; taking the PCV values $\geq 24$ to $46 \%$ as normal for zebu cattle and the PCV was recorded [9, 40].

A thin blood smear on a clean, dry slide is prepared from blood taken from the marginal ear vein or jugular vein. These stains were air-dried, fixed in methyl alcohol (99\%) for 3 minutes, stained with Giemsa dye working solution (1:9) containing phosphate buffer at $\mathrm{pH} 6.8$, and waited for 30 minutes. The stains were washed with tap water to remove additional stains, air-dried and the slides examined with an oil immersion lens of a light microscope.

Giemsa stain and slide microscopy were performed according to OIE, [41]. A thin blood smear was prepared from the blood sample, dried in the air, fixed with absolute methyl alcohol for 3 minutes, stained with $10 \%$ Giemsa for 30 minutes, then examined with an oil immersion lens microscope (100x) and an optical microscope according to Foreyt, [42]. Parasites are identified based on a reference set by Soulsby, [43] and Moretti et al., [44].

\subsection{Data management and Statistical analysis}

Data collected during the study period were stored in Microsoft Excel spreadsheets and analyzed using statistical software called STATA version 13 for Windows. The prevalence was calculated by dividing 
the number of cattle positives for Babesia and found to have ticks by the total number of cattle tested for Babesia and infested with babesiosis. The association of risk factors such as age, sex, physical status, and season of the study period for leptospirosis was assessed using the chi-square test and multivariate logistic regression analysis. In all analyzes, the confidence interval (CI) was maintained at $95 \%$. Statistical significance was set at the p-value less than 0.05 level.

\section{RESULTS}

\subsection{Frequency of Babesiosis in Cattle of the study area}

Among 470 cattle studied for tick-transmitted hemoparasite, $102(21.7 \%)$ were found infected with babesiosis. The Babesia species identified in the current study were Babesia bigemina and B. bovis with an overall prevalence of 15.53\% (73/470) and 6.17\% (29/470) (Figure 1).

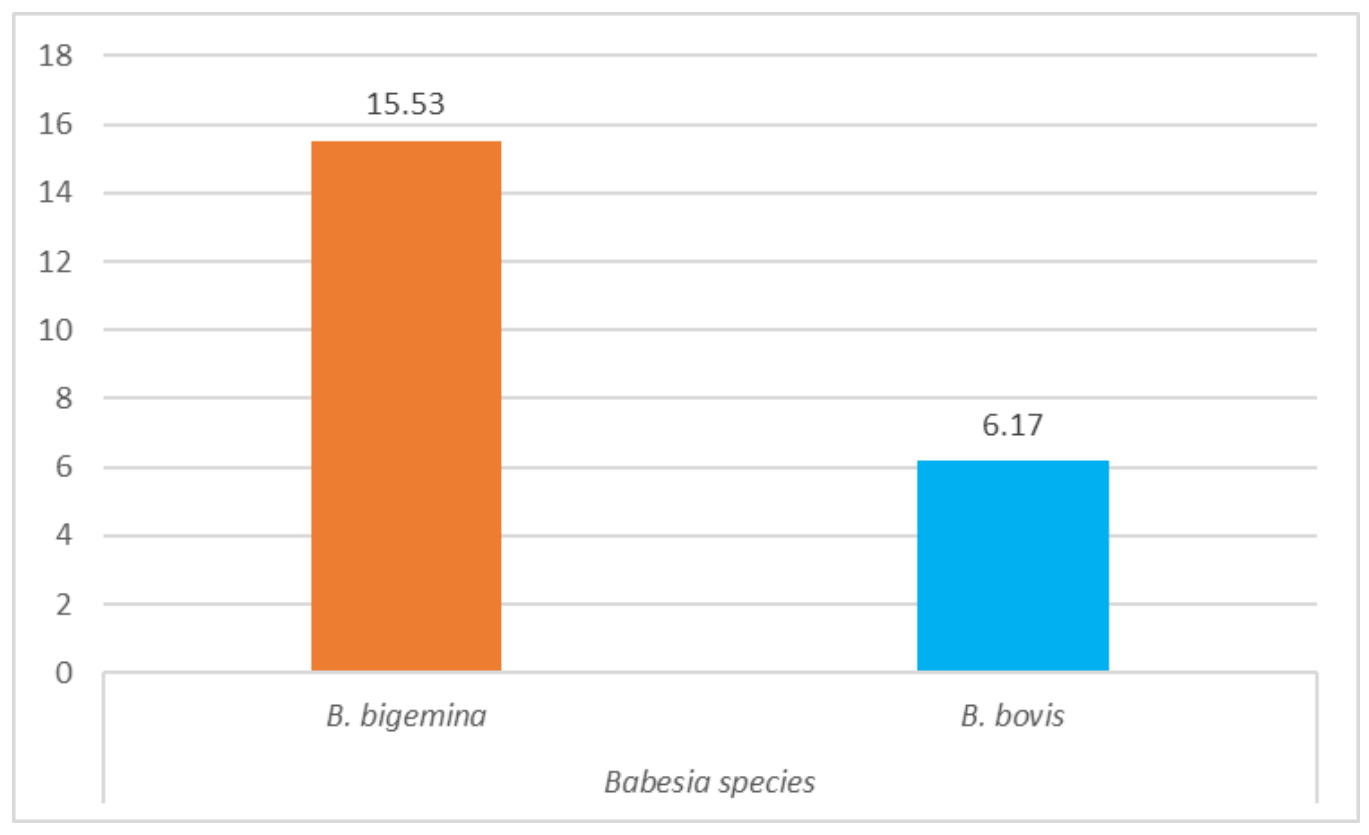

Figure 1: Proportion of bovine babesiosis on basis of babesia Species in the study districts

\subsection{Factors associated with Occurrence of Bovine Babesiosis}

In this study, a relatively higher prevalence of bovine babesiosis was noted in Salamago (50.98\%) and old age $(5.66 \%)$ age groups followed by young $(3.75 \%)$ and adult age $(3.26 \%)$ groups. Besides, the highest infection rates of babesiosis were observed in males $(54.9 \%)$ than females (45.1\%). Also, a higher prevalence of babesiosis was observed in poor body conditioned (68.63\%). The season-wise prevalence of Bovine Babesiosis revealed that it was found equivalent both in the wet season and dry season $(50.0 \%)$ of the year. 
Out of the total cattle which were infected with ticks, 95.1\% (97/102) of them were infected with babesiosis. On the other hand, $4.9 \%$ of the cattle were infected with babesiosis though they were free of tick Infection. Age, sex, body condition score of the cattle, and tick burden were not statistically correlated ( $>0.05)$ with babesiosis. The season and level of tick Infection were found significantly correlated $(p<0.05)$ with the occurrence of babesiosis. To compute the real significant contribution of associated risk factors without cofounding effect on the other, multivariate logistic regression analysis was employed with $95 \% \mathrm{CI}$ and $\mathrm{p}<0.05$, the only season and tick Infection that has been associated significantly $(\mathrm{p}<0.05)$ with the disease but other risk factors has no significant impact on Babesiosis occurrence among different age groups (Table1).

Table 1: Multivariate logistic regression of Host Factors and Prevalence of Bovine Babesiosis

\begin{tabular}{|c|c|c|c|c|c|c|c|}
\hline $\begin{array}{l}\text { Risk } \\
\text { factor }\end{array}$ & Category & $\begin{array}{l}\text { No. of } \\
\text { Tested } \\
\text { Animals }\end{array}$ & Infected (\%) & AOR & $\begin{array}{lcc}95 \% & \text { C. I } \\
\text { [Lower-Upper] }\end{array}$ & $\begin{array}{l}\text { Chi- } \\
\text { square } \\
\left(\mathrm{X}^{2}\right)\end{array}$ & $\begin{array}{l}\text { p- } \\
\text { value }\end{array}$ \\
\hline \multirow[t]{3}{*}{ Age } & Young & 80 & $19(3.75)$ & Ref & Ref & \multirow{3}{*}{2.017} & \multirow{3}{*}{0.37} \\
\hline & Adult & 337 & $68(3.26)$ & 1.013 & $0.25-4.09$ & & \\
\hline & Old & 53 & $15(5.66)$ & 1.63 & $0.28-9.46$ & & \\
\hline \multirow[t]{2}{*}{ Sex } & Male & 251 & $56(54.90)$ & Ref & Ref & \multirow{2}{*}{0.117} & \multirow{2}{*}{0.73} \\
\hline & Female & 219 & $46(45.10)$ & 1.56 & $0.52-4.68$ & & \\
\hline \multirow{3}{*}{$\begin{array}{l}\text { Body } \\
\text { Condition } \\
\text { Score }\end{array}$} & Good & 77 & $22(21.57)$ & 1.30 & $0.25-6.76$ & \multirow{3}{*}{3.69} & \multirow{3}{*}{0.16} \\
\hline & Moderate & 65 & $10(9.80)$ & 1.50 & $0.37-6.12$ & & \\
\hline & Poor & 328 & $70(68.63)$ & Ref & Ref & & \\
\hline \multirow[t]{2}{*}{ Season } & Dry & 190 & $51(50.0)$ & Ref & Ref & \multirow{2}{*}{4.96} & \multirow{2}{*}{0.026} \\
\hline & Wet & 280 & $51(50.0)$ & 0.74 & $0.23-2.35$ & & \\
\hline \multirow{2}{*}{$\begin{array}{l}\text { Tick } \\
\text { Infection }\end{array}$} & Yes & 405 & $97(95.10)$ & 2.22 & - & \multirow{2}{*}{8.71} & \multirow{2}{*}{0.003} \\
\hline & No & 65 & $5(4.90)$ & Ref & Ref & & \\
\hline \multirow{3}{*}{$\begin{array}{l}\text { Tick } \\
\text { Burden }\end{array}$} & Moderate & 2 & $1(0.98)$ & 2.04 & $2.61-0.0000159$ & \multirow{3}{*}{5.83} & \multirow{3}{*}{0.054} \\
\hline & Few & 139 & $39(38.24)$ & - & - & & \\
\hline & None & 329 & $62(60.78)$ & Ref & Ref & & \\
\hline \multirow[t]{2}{*}{ Sites } & Salamago & 247 & $52(50.98)$ & Ref & Ref & \multirow{2}{*}{0.652} & \multirow{2}{*}{0.419} \\
\hline & Dasenech & 223 & $50(49.02)$ & 0.50 & $0.17-1.51$ & & \\
\hline
\end{tabular}

\subsection{Mean PCV in Parasitemic and Aparasitemic Cattle}

In the current study, the PCV of each cattle was assessed to estimate the degree of anemia. The mean PCV value of the parasitemic cattle was $21.49 \%(\mathrm{CI}=21.09-21.89 \%)$ lower than that of the mean PCV value for the aparasitemic animals, $28.29 \%(\mathrm{CI}=28.04-28.54)$. There was a significant variation in the mean PCV value between the infected and non-infected animals $(\mathrm{t}=29.67, p=0.0001)$ (Table 2). 
Table 2: Mean PCV of Infected and Non-Infected Animals found in Dasenech and Salamago District.

\begin{tabular}{|c|c|c|c|c|c|}
\hline Status & No. examined & Mean $\mathrm{PCV} \pm$ SD & t-value & $\begin{array}{c}\text { 95\% Conf. Interval } \\
\text { [Lower-Upper] }\end{array}$ & p-value \\
\hline Parasitemic & 158 & $21.49 \pm 2.56$ & \multirow{3}{*}{29.67} & $21.09-21.89$ & \multirow{3}{*}{0.0001} \\
\hline Non-anemic & 312 & $28.29 \pm 2.23$ & & $28.04-28.54$ & \\
\hline Total & 470 & $26.01 \pm 3.98$ & & $25.65-26.37$ & \\
\hline
\end{tabular}

\subsection{Prevalence of Ixodid Ticks and its association with Babesiosis}

According to the current study, 470 cattle were examined for the presence of tick Infection, and $86.17 \%$ (405/470) were infested with ticks. Moreover, four different tick genera were identified; namely Amblyomma (32.34\%), Boophilus (18.51\%), Hyalomma (18.94\%), and Rhipicephalus (16.38\%), (Table 3). Regarding site prevalence of ticks, the higher prevalence was observed in Salamago 52.10\% (211/405) as compared to Dasenech 47.90\% (194/405) (Figure 2).

Table 3. Overall prevalence of Ticks in Cattle

\begin{tabular}{|l|c|c|}
\hline Tick genera & Frequency & Prevalence (\%) \\
\hline Amblyomma & 152 & 32.34 \\
\hline Boophilus & 87 & 18.51 \\
\hline Hyalomma & 89 & 18.94 \\
\hline Rhipicephalus & 77 & 16.38 \\
\hline Total & $\mathbf{4 0 5}$ & $\mathbf{8 6 . 1 7}$ \\
\hline
\end{tabular}

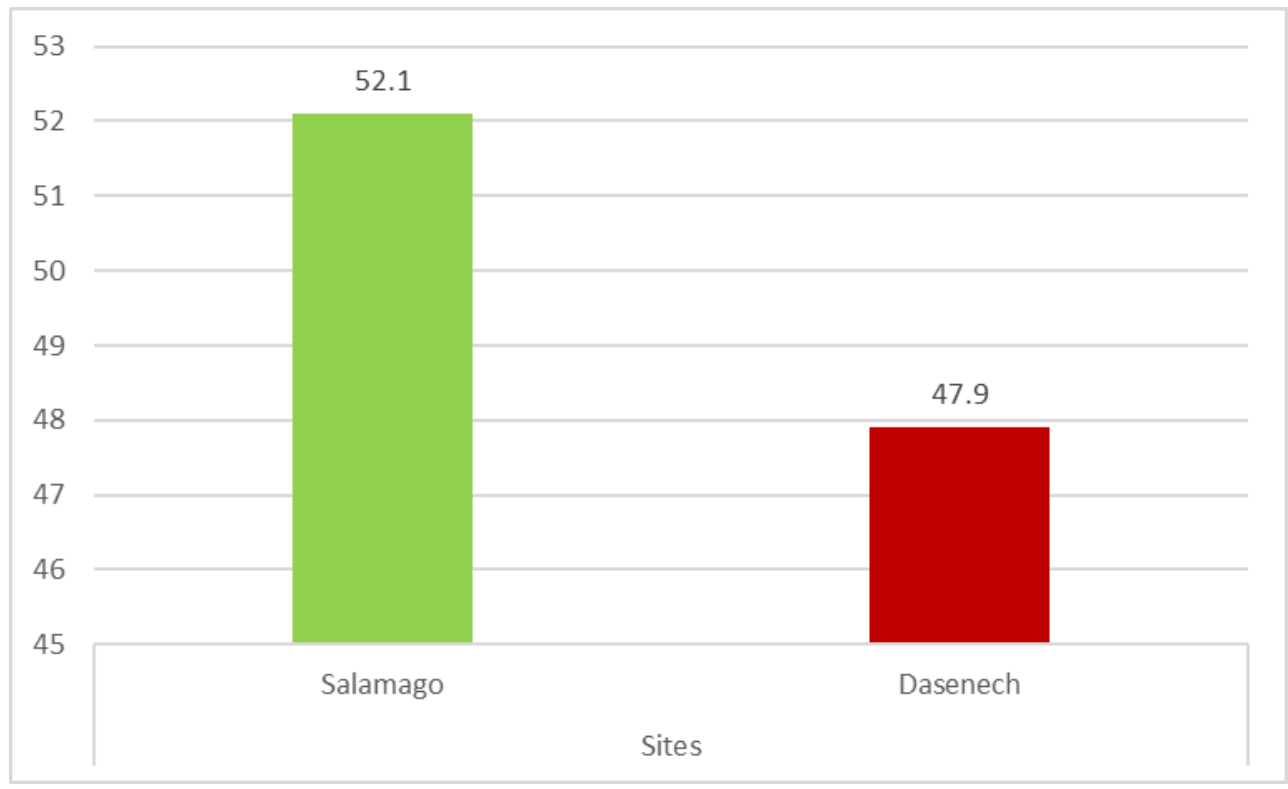


According to the current investigation, four different tick genera (Amblyomma, Boophilus, Hyalomma, and Rhipicephalus) were responsible for the occurrence of babesiosis in cattle. Besides, all these tick genera (Amblyomma, Boophilus, Hyalomma, and Rhipicephalus) have a statistically significant correlation $(\mathrm{p}<0.05)$ with the occurrence of babesiosis in cattle (Table 4).

Table 4: Prevalence of bovine babesiosis with tick genera in Dasenech and Salamago District

\begin{tabular}{|c|c|c|c|c|c|c|}
\hline Tick genera & Category & $\begin{array}{l}\text { No- tested } \\
\text { animal }\end{array}$ & $\begin{array}{l}\text { Babesia } \\
\text { Infected }\end{array}$ & Prevalence $(\%)$ & Chi-square & p-value \\
\hline \multirow{2}{*}{ Amblyomma } & Yes & 152 & 52 & 34.21 & \multirow{2}{*}{20.69} & \multirow{2}{*}{0.000} \\
\hline & No & 318 & 50 & 15.72 & & \\
\hline \multirow{2}{*}{ Boophilus } & Yes & 87 & 37 & 34.62 & \multirow{2}{*}{27.25} & \multirow{2}{*}{0.000} \\
\hline & No & 383 & 65 & 16.97 & & \\
\hline \multirow{2}{*}{ Hyalomma } & Yes & 89 & 32 & 35.96 & \multirow{2}{*}{13.13} & \multirow{2}{*}{0.000} \\
\hline & No & 381 & 70 & 18.37 & & \\
\hline \multirow{2}{*}{ Rhipicephalus } & Yes & 77 & 38 & 49.35 & \multirow{2}{*}{41.43} & \multirow{2}{*}{0.000} \\
\hline & No & 393 & 64 & 16.28 & & \\
\hline
\end{tabular}

\subsection{Factors associated with Ixodid Tick Infection}

In the present study, the overall prevalence of tick infection was $86.17 \%(405 / 470)$. As indicated in the table below, young age $(87.5 \%)$, poor conditioned $(88.11 \%)$, and female $(88.13 \%)$ animals had the highest frequency of tick infection. The frequency of tick infection in the study areas were found higher during the dry season (88.95\%) as compared to the wet season (84.29\%). However, factors such as age, sex, body condition, and season of the year were not statistically correlated with tick infection (Table 5).

The multivariate logistic regression analysis was employed with $95 \% \mathrm{CI}$ and $\mathrm{p}<0.05$, none of the factors has been significantly related $(\mathrm{p}<0.05)$ with tick infection. The odds of adult cattle infected by tick were 0.96 times greater (CI, 0.45-2.03) than old equines 0.68 (CI, 0.25-1.86) while young animals were kept constant. Whereas the odds of female cattle being infected with tick was 1.46 times higher (CI, 0.84-2.52) while male animals were kept constant. Cattle with good body condition were 0.44 times less infected with a tick (CI, 0.37-1.73) than moderately conditioned cattle 0.8 (CI, 0.22-0.85) while poorly conditioned animals were held constant (Table 5).

Table 5. Multivariate logistic regression of host factor and prevalence of Ixodid tick

\begin{tabular}{|c|c|c|c|c|c|c|}
\hline Animal factor & $\begin{array}{l}\text { Frequency } \\
\text { (n) }\end{array}$ & $\begin{array}{l}\text { Tick infested } \\
(\%)\end{array}$ & AOR & $\begin{array}{l}\text { 95\% C.I } \\
\text { [Lower- } \\
\text { Upper] }\end{array}$ & $\begin{array}{l}\text { Chi- } \\
\text { square } \\
\left(\mathbf{X}^{2}\right)\end{array}$ & p-value \\
\hline \multicolumn{4}{|l|}{ Age } & & \multirow{3}{*}{0.57} & \multirow{3}{*}{0.75} \\
\hline Young & 80 & $70(87.5)$ & Ref & Ref & & \\
\hline Adult & 337 & $291(86.4)$ & 0.96 & $0.45-2.03$ & & \\
\hline
\end{tabular}




\begin{tabular}{|c|c|c|c|c|c|c|}
\hline Old & 53 & $44(83.02)$ & 0.68 & $0.25-1.86$ & & \\
\hline \multicolumn{5}{|l|}{ Sex } & \multirow{3}{*}{1.32} & \multirow{3}{*}{0.25} \\
\hline Male & 251 & $212(84.46)$ & Ref & Ref & & \\
\hline Female & 219 & $193(88.13)$ & 1.46 & $0.84-2.52$ & & \\
\hline \multicolumn{2}{|c|}{ Body Condition Score } & & & & \multirow{4}{*}{4.29} & \multirow{4}{*}{0.12} \\
\hline Good & 77 & $61(79.2)$ & 0.44 & $0.22-0.85$ & & \\
\hline Moderate & 65 & $55(84.62)$ & 0.80 & $0.37-1.73$ & & \\
\hline Poor & 328 & $289(88.11)$ & Ref & Ref & & \\
\hline \multicolumn{2}{|l|}{ Season } & & & & \multirow{3}{*}{2.06} & \multirow{3}{*}{0.15} \\
\hline Dry & 190 & $169(88.95)$ & Ref & Ref & & \\
\hline Wet & 280 & $236(84.29)$ & 0.63 & $0.35-1.14$ & & \\
\hline
\end{tabular}

\subsection{Tick Distribution across the animal's Body}

In the current study, a total of 8040 ticks were from different body parts of the animal from 470 examined cattle. Accordingly, the highest proportions of ticks were collected from the scrotum/ udder $(32.10 \%)$ followed by dewlap and neck $(22.06 \%)$, anus, and vulva $(20.14 \%)$, and head and ear (13.84\%). Additionally, the majority of Rhipicephalus species were collected from scrotum/udder (32.91\%) and dewlap and neck (27.09\%) whereas a high quantity of Amblyomma species were collected from scrotum/udder (43.9\%) and brisket (29.03\%). On the other hand, Boophilus species were found around the anus and vulva (35.01\%), as well as the head and ear $(22.75 \%)$. from scrotum/udder (39.78\%), and dewlap and neck (20.43\%) whereas, $32.48 \%$ and $31.19 \%$ of Hyalomma species were the least collected type of tick genera during the current study and mostly found around the anus and vulva region $(29.50 \%)$ and brisket $(23.40 \%)$ (Table 6$)$.

Table 6. Frequency and distribution of tick in various body parts within the study districts

\begin{tabular}{|l|l|l|l|l|l|l|l|l|l|l|}
\hline \multirow{2}{*}{ Body region } & \multicolumn{2}{|l|}{ Rhipicephalus } & \multicolumn{2}{l|}{ Amblyomma } & \multicolumn{2}{l|}{ Boophilus } & \multicolumn{2}{l|}{ Hyalomma } & \multirow{2}{*}{ Total } & \multirow{2}{*}{ Proportion (\%) } \\
\cline { 2 - 10 } & No. & $\mathbf{\%}$ & No. & $\mathbf{\%}$ & No. & $\mathbf{\%}$ & No. & \% & & \\
\hline Head and ear & 806 & 14.39 & 37 & 3.62 & 245 & 22.75 & 25 & 7.59 & 1,113 & 13.84 \\
\hline Dewlap and neck & 1520 & 27.09 & 79 & 7.72 & 126 & 11.69 & 49 & 14.89 & 1,774 & 22.06 \\
\hline Brisket & 248 & 4.41 & 297 & 29.03 & 46 & 4.27 & 77 & 23.40 & 668 & 8.32 \\
\hline Belly and back & 141 & 2.51 & 65 & 6.35 & 67 & 6.22 & 12 & 3.65 & 285 & 3.54 \\
\hline Scrotum/udder & 1847 & 32.91 & 449 & 43.90 & 216 & 20.06 & 69 & 20.97 & 2,581 & 32.10 \\
\hline Anus and vulva & 1049 & 18.96 & 96 & 9.38 & 377 & 35.01 & 97 & 29.50 & 1,619 & 20.14 \\
\hline Total & $\mathbf{5 , 6 1 1}$ & $\mathbf{1 0 0 . 0 0}$ & $\mathbf{1 , 0 2 3}$ & $\mathbf{1 0 0 . 0 0}$ & $\mathbf{1 , 0 7 7}$ & $\mathbf{1 0 0 . 0 0}$ & $\mathbf{3 2 9}$ & $\mathbf{1 0 0 . 0 0}$ & $\mathbf{8 , 0 4 0}$ & $\mathbf{1 0 0 . 0 0}$ \\
\hline
\end{tabular}




\section{DISCUSSION}

In the present study, the overall prevalence rate of babesiosis in cattle was $21.7 \%$. Besides, two species of babesia were identified namely, Babesia bigemina and B. bovis were isolated with the occurrence of $15.53 \%$ and $6.17 \%$, respectively. The prevalence of Babesiosis in the current was comparable with the finding of Lemma et al. [45] who reported 23\% from Jimma Town, South-Western Ethiopia, and Simking et al. [46] who reported 26.6\% from Salakpra Wildlife Sanctuary, Kanchanaburi province.

This finding is higher than the reports of Hamsho et al. [4] 16.9\% from Teltele District, Borana Zone, Southern Ethiopia, Alemayehu [47] who reported 12\% in Jimma district, Western Ethiopia, Bariso, and Worku [48] who reported 11.4\% overall haemoparasitemia in Arsi, Central Ethiopia, Solomon and Tanga [49] 6.51\% from cattle of Alle district, Southwestern Ethiopia, Ayaz et al. [50] 9.9\% from Kohat and Karak District, Khyber Pakhtunkhwa Pakistan and Ahmad and Hashmi, [51] 6.6\% from Lahore, North-East Pakistan.

The prevalence of babesiosis in the current research was much higher than the studies of Shane et al. [27] 1.6\% in Tiyo District, Arsi Zone, Oromia Region, Waktole et al. [52] 3.64\% in cattle of Meki and Batu Towns, Oromia, Ethiopia, Wodajnew et al. [53] with a prevalence of 1.5\% from Assosa district, Benishangul Gumuz Regional State, Ethiopia, Ola-Fadunsin et al. [54] 1.2\% in Nigeria and Sitotaw et al. [8] 0.3\% from Cattle of Debre-Zeit, Central Ethiopia.

However, this result was lower than the previous report of Rahman et al. [55] 42\% prevalence reported from Malaysia, Mohammed and Ebied, [56] 40\% from Benha, Qalubia Governorate, North Eastern Egypt. This variation in the prevalence of babesiosis in cattle could be attributed to differences in the study area, use of acaricides during tick Infection, the type of diagnosis followed, proper use of antiparasitic drugs, management systems of cattle on the focus area, and sampling seasons of the year, the land use of the area, which is different among the study areas. In addition, the sensitivity of the tests used, the distribution of infected vectors, the accessibility of animals to wildlife reserves and parks and forest areas containing tick vectors causing Babesiosis. [57, 58]. Other causes of variation may be due to different geographical conditions and or due to different breeds of cattle studied [59].

According to the current study, a higher infection rate of $B$. bigemina $(15.53 \%)$ was recorded than $B$. bovis $(6.17 \%)$. This finding was in line with the previous report of Waktole et al. [52] in terms of species of babesia B. bigemina (3.38\%) and B. bovis $(0.26 \%)$ yet, the prevalence was lower than the current finding, whereas Solomon and Tanga, [49] reported Babesia bovis (6.51\%) as the only hemoparasite of cattle in Alle District, Southwestern Ethiopia which is comparable with the finding of current finding.

The results of the present research disagree with the studies of Rahman et al. [55] who reported a prevalence of 17\% (B. bovis) and 16\% (B. bigemina) from Malaysia, Hamsho et al. [4] who reported a prevalence of $9.9 \%$ (B. bovis) and 7\% (B. bigemina) from Borana, Ethiopia, Wodajnew et al. [53] who 
reported a prevalence of $1.24 \%$ (B. bovis) and 0.29\% (B. bigemina) from Assosa Ethiopia. Different investigations have also revealed that cattle infected with $B$. bovis remain carriers for long periods, while those infected with $B$. bigemina remain carriers for only a few months $[11,58]$.

In the present study, a higher prevalence of bovine babesiosis was noted in old age (5.66\%) age groups than young (3.75\%) and adult age (3.26\%) groups. Similarly, Waktole et al. [52] from Maki and Batu area and Ayaz et al., [50] from Pakistan reported the highest prevalence of babesiosis in old age with a prevalence of $7.5 \%$ and $13.4 \%$. However, the results of this study disagree with the report of Amorim et al. [60] who identified that calves were more susceptible to Babesia species when compared to adult cows. The difference is that young animals, especially calves under 6 months of age, are more likely to be more resistant to mild infections than older animals because they gain acquired immunity from feeding their first milk. On the other hand, low frequency in young animals is due to limited grazing by young animals may reduce the likelihood of exposure to this vector [61].

The present study revealed that the highest babesia infection was observed in males (54.9\%) than females (45.1\%). Similarly, Solomon and Tanga [49] reported higher babesiosis in males (7.09\%) cattle of Alle district, Southwestern Ethiopia. Nevertheless, this result disagrees with the report of Waktole et al. [52] who reported 4.4\% from the Maki and Batu area, and Kocan et al. [62] who found a higher prevalence of babesiosis in females $11.2 \%$ than male cattle $6.96 \%$.

Regarding seasonal variation of Babesiosis in cattle, the prevalence was recorded both in the wet season and dry season $(50.0 \%)$ of the year. The season was found significantly correlated $(\mathrm{p}<0.05)$ with babesiosis. In line with the present study, Kamani et al, [61] also reported the prevalence of babesiosis was highest in summer and autumn, less in spring and lower in cattle in winter.. In contrast to the current investigation, Solomon and Tanga [49] reported higher babesiosis $(9.46 \%)$ during the wet than dry (4.66\%) season. Waktole et al. [52] also reported higher infection of babesiosis in cattle during the wet $(3.8 \%)$ season.

All studies to date have been conducted from the end of the dry season to the beginning of the rainy season. However, in this study, all samples were taken from mid-winter to late- autumn. This means that important factors affect both vector velocity and seasonal variation, high humidity, and temperature. Also, the prevalence of parasitic tick-borne diseases is low in the dry season and highest in the rainy season [63].

In the present study, out of the total cattle which were infected with ticks, $95.1 \%(97 / 102)$ of cattle were infected with babesiosis. There was a strong correlation $(p<0.05)$ between babesiosis and tick vectors. The presence of diseases caused by hemoparasite is broadly related to the presence and distribution of the vectors $[9,64]$.

In the current study, there was a statistically significant $(p=0.0001)$ difference in the mean PCV value between the parasitemic cattle $(21.49 \%)$ and non-infected animals $(28.29 \%)$. The mean PCV value of 
infected cattle was $19.29 \%$ that shows below normal value. This suggests that anemia is a clinical sign of babesia infection and the parasite invades the red blood cells to cause hemolysis. This was in line with the previous report of Waktole et al. [52] and Sitotaw et al., [8]. Anemia develops as a result of blood hemolysis and hemolysis occurs due to mechanical damage by trophozoite to RBC when multiplied by binary fission, phagocytosis of infected RBC by host immune system, and toxic substances secreted by the parasites [65].

According to the current study, the prevalence of tick Infection was $86.17 \%(405 / 470)$. This was comparable with the previous finding of Ayana et al. [66] who reported $89.89 \%$ in Yabello district, Borana zone, Oromia, Ethiopia, Mesfin et al. [67] 89.1\% in Wolaita Zone, the finding of Kumisa et al. [68] 68.8\% in Dandi district, Oromia, Abera et al, [5] 97.8\% in cattle from Bedelle district, Southwestern Ethiopia, Meaza et al. [69] 211 (91.7\%) in Bahir Dar extensive farms, Shichibi et al. [70] in Saylem 502 (88.54\%), Gesha 183 (91.50\%) and Masha 149 (78.84\%) in districts of Southern Ethiopia, Kemal., et al. [18] 2024 (75.7\%) in Arbegona District, Southern Ethiopia, Teshome et al. [20] 270 (70.31\%) in Bishoftu town, Wogayehu et al. [71] 68.12\% in the high land of Decha woreda. Tamerat et al. [72] 82\% in Bedelle district, Oromia Regional State, Alemu, et al., [73] 81.25\% in North-West Ethiopia, and Wolde and Mohamed [74] 65.5\% in Sodo zuriya districts, Wolaita Zone, de Castro [75] where it was stated that more than $80 \%$ of the cattle studied were ticks-infested.

The overall prevalence of tick Infection in cattle in the current study was higher than Wasihun and Doda [76] 61\% in Humbo district, Solomon and Tanga [49] 36.19\% in Alle district, Meseret et al. [77] who reported 59.6\% prevalence in Harari region, Eastern Ethiopia, Fesseha and Mathewos, [17] 42.2\% in Hosana district, Hadiya zone, Tiki and Addis [78] with 25.64\% tick infection prevalence in Holeta district, Waktole et al. [52] 29.4\% in Maki and Batu area, and Zelalem et al. [22] 146 (38\%) in the Chiro district. This may be due to differences in study area coverage and environment. It can also be due to factors such as animal health practice, temperature, and humidity that promote survival and growth of ticks during their development, acaricide application as control methods, low level of awareness of farmers and the proportion of ticks [79] [80].

In the present study, tick infection was higher at a young age (87.5\%) which was agreed with the report of Kemal., et al. [18] also stated an occurrence of $98.4 \%$ in Arbegona District, Southern Ethiopia, Yalew et al. [81] described that young age cattle (43.41\%) were highly affected than other age categories. There are several possible reasons such as young bulls are kept at home until they get better, so they are less likely to get ticks than adult cattle kept in an extensive husbandry system.

However, this was not consistent with the previous report of Ayana et al. [66] in the Yabello district stated a higher infection rate (93.27\%) in adults than other age groups, Fesseha and Mathewos, [17] where a higher tick prevalence $28 \%$ (77/275) was recorded in adult one than other age groups, Shichibi et al. [70] with a higher prevalence in adult (93.97\%) than young (78.71\%), Meaza et al. [69] with high frequency with increasing age category; adult (62.7\%) and young (85.1\%), Ayana et al, [82] and Okello-Onen et al. [83]. This may be related to the fact that the larger body size and the ticks feed on 
many surfaces of the body of the animals. Therefore, older animals are often susceptible to ticks because hard ticks have been attached to the host for a long time. Likewise, as age increases, the body's immunity starts to decline, which is true in the case of old animals.

In the present study, the most dominant tick genera were Amblyomma (32.34\%), followed by Hyalomma (18.94\%), Boophilus (18.51\%), and Rhipicephalus (16.38\%). This was in line with the earlier report by Kemal et al. [18] in Arbegona District, Wasihun and Doda [76] in Humbo district, Ayalew et al. [15] in central Oromia, and Yehualashet et al. [84] at Haramaya University where Amblyomma was identified as the major tick genera. In contrast to this result, Ayana et al. [66] and Waktole et al. [52] reported Rhipicephalus as the dominant tick genera. Wasihun and Doda, [76] also reported that only three tick species were predominantly found in Ethiopia. Besides, according to Shane et al. [27], Boophilus was identified as the main tick species in Tiyo District. This may be due to the different seasons in which the survey was conducted $[5,75]$.

Females were more infected with different tick genera. Yet, the difference was found statistically insignificant ( $p>0.05)$ between the sex of cattle. This result is in line with the Onu and Shiferaw, [85] in Benchi Maji however, it was not in line with the earlier report of Bossen and Abdu, [86] in Assosa who reported tick infection significantly affects both sex groups.

The current study revealed that poor conditioned $(88.11 \%)$ had the highest prevalence of tick Infection and this was not significantly $(p>0.05)$ related to tick infection. The result was in line with the finding of Kassa and Yalew, [35] in and around Haramaya district and Shiferaw and Onu, [34] who reported no significant correlation ( $p>0.05$ ) exist the ticks prevalence and animal's body condition score. This was against the finding of Tiki and Addis, [78].

In the current study, a total of 8040 ticks were collected from various parts of the animal body. The highest tick frequency was gathered from the scrotum/ udder $(32.10 \%)$ followed by dewlap and neck (22.06\%), anus and vulva (20.14\%), and head and ear (13.84\%). Also, the majority of Rhipicephalus species were collected from scrotum/udder (32.91\%) and dewlap and neck (27.09\%). However, Ayana et al. [66] from the Yabello district reported a high proportion of ticks from the Head and ear (34.57\%) region. Furthermore, Amblyomma species were collected in a high proportion of from scrotum/udder and brisket, whereas Rhipicephalus species from head and ear and anus and vulva, Hyalomma species from scrotum/udder, anus and vulva and dewlap and neck, and Boophilus species from anus and vulva part of the body.

\section{CONCLUSION}

The present findings indicated that bovine babesiosis is one of the major hemoparasitic protozoan infections of cattle that circulate in the Dasenech and Salamago District. Tick vectors such as Amblyomma, Boophilus, Hyalomma, and Rhipicephalus species were also found in the study districts. Babesia bigemina followed by Babesia bovis were the major Babesia species that cause babesiosis in 
cattle. Since the prevalence of babesiosis is directly related to its tick vectors, seasonal cattle and pasture treatment before and after the rainy season and regular surveys of tick vectors and awareness of their control measures should be provided to pastoralists. In order to keep the good management practices, improve the prevailing problems, and encourage the improvement of livestock production practically in the study districts, it is essential to customize appropriate and integrated tick control measures with improved management practice and tactical treatment of overt bovine babesiosis clinical cases.

\section{Abbreviations}

AOR- Adjusted Odds Ratio, CSA-Central Statistical Authority, EDTA-Ethylene Diminetetra acetic acid, OIE-Office of des International Epizootics, PCV-Packed Cell Volume, RBC-Red Blood Cell, RPM-Revolution per Minute

\section{Funding}

This work was not supported by any funding source or institution.

\section{Availability of data and materials}

The datasets used and analyzed during the current study are available from the corresponding author on request.

\section{Competing interests}

All authors declared no competing conflict of interest.

\section{Ethics approval and consent to participate}

Ethical approval for this research was obtained from the Wolaita Sodo University Research Ethics and Review Committee. Before collecting samples, verbal consent was also pursued from the Cattle owners to take samples from their cattle and adopted strict hygienic measures.

\section{REFERENCES}

1. Central Statistical Agency, Agricultural Sample Survey 2017/2018, Report on livestock and livestock characteristics, Statistical Bulletin 587, April 2018. 2018: Addis Ababa, Ethiopia, .

2. Houseman, R.M., Guide to ticks and tick-borne diseases. Integrated Pest Management. 2013, Columbia, MO 65211: University of Missouri Extension, Extension Publications.

3. Mekonnen, S., I. Hussein, and B. Bedane, 'The distribution of ixodid ticks (Acari: Ixodidae) in central Ethiopia. Onderstepoort Journal of Veterinary Research, 2001. 68: p. 243-251.

4. Hamsho, A., et al., A cross-sectional study of bovine babesiosis in Teltele District, Borena Zone, Southern Ethiopia. J Veterinar Sci Technol, 2015. 6(230): p. 2.

5. Abera, M., et al., Survey of ixodid ticks in domestic ruminants in Bedelle district, Southwestern Ethiopia. Tropical animal health and production, 2010. 42(8): p. 1677-1683.

6. Kumsa, B., Y. Abiy, and F. Abunna, Ectoparasites infesting dogs and cats in Bishoftu, central Oromia, Ethiopia. Veterinary Parasitology: Regional Studies and Reports, 2019. 15: p. 100263. 
7. Hunfeld, K., A. Hildebrandt, and J. Gray, Babesiosis: Recent insights into an ancient disease. Int J Parasitol, 2008. 38: p. 1219-1237.

8. Sitotaw, T., et al., Epidemiological significance of major hemoparasites of ruminants in and around Debre-Zeit, Central Ethiopia. Journal of Parasitology and Vector Biology, 2014. 6(2): p. 16-22.

9. Radostits, O.M., et al., Veterinary Medicine E-Book: A textbook of the diseases of cattle, horses, sheep, pigs and goats. 2006: Elsevier Health Sciences.

10. Iseki, H., et al., Seroprevalence of Babesia infections of dairy cows in northern Thailand. Veterinary parasitology, 2010. 170(3-4): p. 193-196.

11. Bock, R., et al., Babesiosis of cattle. Parasitology, 2004. 129(S1): p. S247-S269.

12. Russell, R.C., D. Otranto, and R.L. Wall, The encyclopedia of medical and veterinary entomology. 2013: CABI.

13. Daniel, E., S. Robert, and L. William, Medical and Veterinary Entomology. 2012, Elsevier Science: USA. p. 517-558.

14. Nibret, M., B. Basaznew, and F. Tewodros, Hard ticks (Ixodidae): species composition, seasonal dynamics and body site distribution on cattle in Chilga District, Northwest Ethiopia. Asian Journal of Agricultural Sciences, 2012. 4(5): p. 341-345.

15. Ayalew, T., Y. Hailu, and B. Kumsa, Ixodid ticks infesting cattle in three agroecological zones in central Oromia: species composition, seasonal variation, and control practices. Comparative Clinical Pathology, 2014. 23(4): p. 1103-1110.

16. Bayew, K. and L. Ewnetu, Prevalence of Tick Infestation of Bovine-Case in Janamora Wereda. International Journal of Agriculture and Agribusiness, 2019. 2(1): p. 91-97.

17. Fesseha, H. and M. Mathewos, Prevalence and Identification of Bovine Ixodid Tick with their Associated Risk Factors in Hosana district, Hadiya Zone Southern Ethiopia. Acta Scientific Pharmaceutical Sciences, 2020. 4(6): p. 20-25.

18. Kemal, J., N. Tamerat, and T. Tuluka, Infestation and Identification of Ixodid Tick in Cattle: The Case of Arbegona District, Southern Ethiopia. Journal of veterinary medicine, 2016. 2016: p. 7.

19. Kumsa, B., M. Geloye, and K. Beyecha, Ectoparasites of sheep in three agro-ecological zones in central Oromia, Ethiopia. Onderstepoort Journal of Veterinary Research, 2012. 79(1): p. 1-7.

20. Teshome, T., Y. Deneke, and N. Ibrahim, Prevalence and Species Composition of Ticks Infesting Cattle In and Around Bishoftu Town, Oromia Region, Ethiopia. Global Veterinaria, 2016. 16(3): p. 238-246.

21. Wogayehu, Y., et al., Epidemiological Study of Ticks and their Distribution in Decha Woreda of Kafa zone, SNNPRS. International Journal of Research in Agriculture and Forestry, 2016. 3(6): p. 7-19.

22. Zelalem, A., et al., Prevalence of Bovine Hard Ticks in Chiro District, West Hararghe Zone, East Oromiya. Acta Parasitol Globalis 2016. 7(2): p. 66-73.

23. Eyo, J.E., et al., Survey of tick infestation of cattle at four selected grazing sites in the tropics. Global Veterinaria, 2014. 12(4): p. 479-486.

24. Ababa, H., et al., Study on the status of Bovine Tick Infestation, in Guba-Koricha District in West Hararghe Zone, East-Ethiopia. International Journal of Research-GRANTHAALAYAH, 2017. 5(4): p. 202213.

25. Belayneh, N. and B. Bogale, Prevalence of Ixodid Ticks on Cattle in and Around Jabitehnan Woreda, North Western Ethiopia. Acta Parasitologica Globalis 2016. 7(3): p. 121-125.

26. Chali, E., M. Melaku, and J. Negero, Study on cattle tick species frequency distribution in and around Jimma province of Ethiopia. Journal of parasitology and Vector biology, 2017. 9(4): p. 34-38.

27. Shane, T., T. Gunse, and F. Woldemariyam, Identification of Tick and Tick Borne Hemo-Parasites in Tiyo District, Arsi Zone, Oromia Region. J Vet Sci Technol, 2017. 8(418): p. 2.

28. Central Statistical Agency, Report on livestock and livestock characteristics. The Federal Democratic Republic of Ethiopia, Private Peasant Holdings, Statistical Bulletin 570. 2017, CSA: Addis Ababa, Ethiopia.

29. Johnson, R., The stockmans hand book. 2nd ed, ed. M.E. Ensminger. 1998. 
30. Wakeman, D. and J. Pace, Determining the age of cattle by their teeth. Journal of the American Veterinary Medical Association, 1983. 121: p. 483.

31. Beverly, J., Reproduction in beef cattle as related to nutrition and body condition, in Kentucky roundup of reproductive efficiency in beef cattle. 1985. p. 1-12.

32. Teka, W., D. Terefe, and A. Wondimu, Prevalence study of bovine trypanosomosis and tsetse density in selected villages of Arbaminch, Ethiopia. Journal of Veterinary Medicine and Animal Health, 2012. 4(3): p. 36-41.

33. Thrusfield, M., Veterinary epidemiology. 2018: John Wiley and Sons.

34. Shiferaw, T. and S. Onu, Prevalence of ectoparasite infestations of cattle in Bench Maji zone, southwest Ethiopia. Vet World, 2013. 6(6).

35. Kassa, S. and A. Yalew, Identification of Ixodide ticks of cattle in and around Haramaya district, Eastern Ethiopia. Scientific Journal of Crop Science, 2012. 1(1): p. 32-38.

36. Paris, J., M. Murray, and F. McOdimba, A comparative evaluation of the parasitological techniques currently available for the diagnosis of African trypanosomiasis in cattle. Acta tropica, 1982. 39(4): $p$. 307-316.

37. Turkson, P.-K. and E.Y. Ganyo, Relationship between haemoglobin concentration and packed cell volume in cattle blood samples. Onderstepoort Journal of Veterinary Research, 2015. 82(1): p. 01-05.

38. Velguth, K.E., M.E. Payton, and J.P. Hoover, Relationship of hemoglobin concentration to packed cell volume in avian blood samples. Journal of Avian Medicine and Surgery, 2010. 24(2): p. 115-121.

39. Woo, P., The haematocrit centrifuge technique for the diagnosis of African trypanosomiasis. Acta tropica, 1970. 27(4): p. 384-6.

40. Samdi, S., et al., Prevalence of trypanosomosis in cattle at slaughter in Kaduna central abattoir. Asian Journal of Animal Sciences, 2011. 5(2): p. 162-165.

41. OIE, OIE Reference Laboratory for Animal Trypanosomoses of African Origin, in Compendium of Standard Diagnostic Protocols for Animal Trypanosomoses of African Origin. 2017, Office International des Epizooties (OIE): Montpellier, France.

42. Foreyt, W.J., Veterinary parasitology reference manual. 2013: John Wiley \& Sons.

43. Soulsby, E., Helminthes, arthropods and protozoa of domestic animals. 1986, Bailliers Tindall: London, UK. p. 247-250.

44. Moretti, A., et al., Prevalence and diagnosis of Babesia and Theileria infections in horses in Italy: a preliminary study. The Veterinary Journal, 2010. 184(3): p. 346-350.

45. Lemma, F., A. Girma, and D. Demam, Prevalence of bovine babesiosis in and around Jimma Town south western Ethiopia. Advances in biological research, 2016. 9: p. 338-439.

46. Simking, P., et al. Prevalence and factors associated with Babesia spp. infections of cattle raised nearby forest in Salakpra Wildlife Sanctuary, Kanchanaburi province. in Agricultural sciences: leading Thailand to world class standards. Proceedings of the 52nd Kasetsart University Annual Conference, 4-7 February 2014, Kasetsart University, Thailand. Vol. 2: Animals, Veterinary Medicine. 2014. Kasetsart University.

47. Alemayehu, C., Study on bovine babesiosis and its associatted risk factors in and around Jimma town, southwest Ethiopia, in Department of Veterinary Medicine. 2014, Jimma University: Jimma, Ethiopia. p. 38.

48. Bariso, M. and Y. Worku, Cattle ticks and tick borne haemoparasite species identification and associated risk factors in two districts of West Arsi Zone, Ethiopia. Journal of Veterinary Science and Animal Husbandry, 2018. 6(5): p. 501.

49. Solomon, A. and B.M. Tanga, The First Investigation of Tick Vectors and Tick-Borne Diseases in Extensively Managed Cattle in Alle District, Southwestern Ethiopia. Veterinary Medicine International, 2020. Volume 2020: p. 8.

50. Ayaz, S., et al., Epidemiology and Molecular Detection of Babesiosis in Household Dairies in Districts Kohat and Karak. Life Science Journal, 2013. 10(10s). 
51. Ahmad, N. and H. Hashmi, A comparative study on the incidence of ticks and ticks borne diseases on local and crossbred cattle in Malakand agency. J. Anim. PI. Sci, 2007. 17(3-4): p. 56-58.

52. Waktole, H., et al., Study on Bovine Babesiosis in and Around Meki and Batu Towns, Oromia, Ethiopia. Global Veterinaria, 2017. 19(4): p. 607-615.

53. Wodajnew, B., et al., Study on the prevalence of bovine babesiosis and its associated risk factors in and around Assosa Woreda, Benishangul Gumuz regional state, western Ethiopia. Researcher, 2015. 7(8): p. 33-39.

54. Ola-Fadunsin, S.D., et al., Occurrence of parasitic diseases of horses in Osun state, Nigeria: $a$ retrospective evaluation. Alexandria Journal for Veterinary Sciences, 2018. 56(1): p. 175-181.

55. Rahman, W., Y. Lye, and P. Chandrawathani, The seroprevalence of bovine babesiosis in Malaysia. Tropical biomedicine, 2010. 27(2): p. 301-307.

56. Mohamed, G. and M. Ebied, Epidemiological studies on bovine Babesiosis and Theileriosis in Qalubia governorate. Benha Veterinary Medical Journal, 2014. 27(1): p. 36-48.

57. Homer, M.J., et al., Babesiosis. Clinical microbiology reviews, 2000. 13(3): p. 451-469.

58. Vannier, E. and P.J. Krause, Babesiosis, in Hunter's Tropical Medicine and Emerging Infectious Diseases. 2020. p. 799-802.

59. Nasir, A., H. Hashmi, and M. Afzal, Prevalence of haemoparasites in exotic cattle. Int J Agri Biol, 2000. 2(4): p. 402-403.

60. Amorim, L.S., et al., Bovine babesiosis and anaplasmosis complex: diagnosis and evaluation of the risk factors from Bahia, Brazil. Revista Brasileira de Parasitologia Veterinária, 2014. 23: p. 328-336.

61. Kamani, J., et al., Prevalence and significance of haemoparasitic infections of cattle in North-Central, Nigeria. Veterinary World, 2010. 3(10): p. 445-448.

62. Kocan, K.M., et al., The natural history of Anaplasma marginale. Veterinary parasitology, 2010. 167(24): p. 95-107.

63. Gebre, S., M. Nigist, and B. Kassa, Seasonal variation of ticks on calves at Sebeta in Western Shoa Zone Ethiopia. Ethiopian Veterinary Journal, 2003. 7(1): p. 17-30.

64. Alekaw, S., Distribution of ticks and tick-borne diseases at Metekel Ranch. Ethiop Vet J 1998. 4(40-59).

65. Ibrahim, A., et al., Comparative molecular and conventional detection methods of Babesia equi (B. Equi) in Egyptian Equine. Glob. Vet, 2011. 7(2): p. 201-210.

66. Ayana, M., et al., Study on the distribution of ixodid ticks of cattle in pastoral areas of Yabello district, Borana zone, Oromia, Ethiopia. Parasite Epidemiology and Control, 2021: p. e00200.

67. Mesfin, M., S. Tewedros, and Y. Yemisrach, Study on the ixodid ticks of domestic ruminants in three selected districts of Wolaita zone, Southern Ethiopia. Global Journal of Science Frontier Research: D Agricultural and Veterinary, 2018. 18: p. 32-38.

68. Kumisa, M., et al., Prevalence and identification of bovine ixodid tick in Dandi district, west Shoa zone, Oromia, region, Ethiopia. SOJ Veterinary Sciences, 2017. 3(5): p. 1-8.

69. Meaza, G., M. Abdu, and K. Yisehak, Determination of the prevalence of ixodid ticks of cattle breeds, their predilection sites of variation and tick burden between different risk factors in Bahir Dar, Ethiopia. Global Veterinaria, 2014. 13(4): p. 520-529.

70. Shichibi, T.H., M.S. Edere, and T.F. Mekitet, Bovine Ixodid Ticks: Prevalence, Distribution and Associated Risk Factors in Saylem, Gesha and Masha Districts, Southern Ethiopia. Advances in Biological Research, 2017. 11(5): p. 265-270.

71. Wogayehu, Y., et al., Epidemiological Study of Ticks and their Distribution in Decha Woreda of Kafa zone, SNNPRS. International Journal of Research and Scientific Innovation (IJRSI), 2016. 7(6 ): p. 7-19.

72. Tamerat, N., et al., Identification and prevalence of ixodid tick in bovine at Bedele district, Oromiyia Regional State, Western Ethiopia. J. Parasitol. Vector Biol, 2015. 7(8): p. 156-162.

73. Alemu, G., et al., Prevalence of ixodid ticks on cattle in Northwest Ethiopia. Acta Parasitol. Glob, 2014. 5(2): p. 139-145. 
74. Wolde, A. and A. Mohamed, Prevalence of ixodid ticks on Bovine in Sodo zuriya districts, Wolaita Zone, Ethiopia. Acta Parasitologica Globalis, 2014. 5(3): p. 188-197.

75. De Castro, J., Tick survey, Ethiopia, in A survey of the tick species in Western Ethiopia, including previous findings and recommendations for further tick surveys in Ethiopia. 1994, Food and Agriculture Organization: Rome, Italy. p. 1-83.

76. Wasihun, P. and D. Doda, Study on prevalence and identification of ticks in Humbo district, Southern Nations, Nationalities, and People's Region (SNNPR), Ethiopia. J. Vet. Med. Anim. Hlth, 2013. 5(3): p. 73-80.

77. Meseret, M., D. Tilaye, and W. Akinaw, Study on prevalence of major ixodid ticks of cattle in selected sites of Harari region, eastern Ethiopia. Ecology and Evolutionary Biology, 2017. 2(6): p. 96-100.

78. Tiki, B. and M. Addis, Distribution of ixodid ticks on cattle in and around Holeta town, Ethiopia. Global veterinaria, 2011. 7(6): p. 527-531.

79. Nath, S., et al., Impact and management of acaricide resistance: pertaining to sustainable control of ticks. International Journal of Livestock Research, 2018. 8(10): p. 46-60.

80. Bianchi, M.W., N. Barre, and S. Messad, Factors related to cattle infestation level and resistance to acaricides in Boophilus microplus tick populations in New Caledonia Veterinary Parasitology, 2003. 112(1-2): p. 75-89.

81. Yalew, A., S. Adugna, and M. Keffale, Identification of Major Ixodid Ticks on Cattle in and Around Haramaya Town, Eastern Hararghe, Ethiopia. Acta Parasitol. Glob, 2017. 8(1): p. 09-16.

82. Ayana, D., E. Eshetu, and F. Abunna, Survey of Ixodid ticks on cattle in Borana pastoral area, Ethiopia. Acta Parasitologica Globalis, 2013. 4(1): p. 14-23.

83. Okello-Onen, J., S.M. Hassan, and E. Suliman, Taxonomy of African ticks: an identification manual. 1999, Nairobi, Kenya: International Centre of Insect Physiology and Ecology (ICIPE). 124.

84. Yehualashet, T., et al., Preliminary Observation on Ticks: Seasonal Dynamics and Resistance of Three Indigenous and Three Cross-Bred Cattle in Ethiopia. Bulletin of animal Health and production in Africa, 1995. 43(2): p. 105-114.

85. Onu, S. and T. Shiferaw, Prevalence of ectoparasite infestations of cattle in Bench Maji zone, southwest Ethiopia. Veterinary World, 2013. 6(6): p. 291-294.

86. Bossena, F. and M. Abdu, Survey on the distribution of tick species in and around Assosa Town, Ethiopia. Research Journal of Veterinary Sciences, 2012. 5(2): p. 32-41. 